https://doi.org/10.36105/iut.2019n29.11

\title{
O PARADIGMA DA SUSTENTABILIDADE COMO ELEMENTO PROPULSOR DO ESTADO SOCIOAMBIENTAL DE DIREITO
}

\author{
EL PARADIGMA DE LA SOSTENIBILIDAD COMO \\ ELEMENTO PROPULSOR DEL ESTADO SOCIO AMBIENTAL \\ DE DERECHO
}

\section{THE SUSTAINABILITY PARADIGM AS A DRIVING FORCE OF THE SOCIO-ENVIRONMENTAL STATE OF LAW}

\author{
Nathalia Batschauer D'Avila Martins* \\ Universidade do Vale do Itajaí, Brasil \\ nathaliabdavila@edu.univali.br \\ Heloise SiqueIra Garcia** \\ Universidade do Vale do Itajaí, Brasil \\ heloisegarcia@univali.br
}

\section{RESUMO:}

O objetivo da presente pesquisa é a análise da necessidade de consolidação de um novo modelo de Estado de Direito, frente às atuais condições globais de crise ecológica e social. O método utilizado para a pesquisa foi o método indutivo. Durante o trabalho será analisada a evolução histórica dos Estados de Direito Liberal, Social e Democrático, e a forma como essa evolução está ligada às mudanças de paradigma suscitados pelas crises vivenciadas pela humanidade. Considerando a atual crise ambiental e social vivida mundialmente, será estudada a

\footnotetext{
Mestre em Ciência Jurídica pelo Programa de Pós-Graduação Stricto Sensu em Ciência Jurídica - PPCJ da Universidade do Vale do Itajaí - UNIVALI, Itajaí, Santa Catarina, Brasil. Advogada. E-mail: nathaliabdavila@, edu.univali.br ou nathaliabdavila@gmail.com

** Doutora em Ciência Jurídica pelo PPCJ - UNIVALI. Doutora em Derecho pela Universidade de Alicante - Espanha. Pós-doutoranda com bolsa concedida pela CAPES. Mestre em Ciência Jurídica pelo PPCJ UNIVALI. Mestre em Derecho Ambiental y de la Sostenibilidad pela Universidad de Alicante - Espanha. Pós-graduada em Direito Previdenciário e do Trabalho pela UNIVALI; e em Ensino e Tutoria a Distância pela Faculdade AVANTIS. Graduada em Direito pela Universidade do Vale do Itajaí - UNIVALI. Professora do Programa de Pós-Graduação Stricto Sensu em Ciência Jurídica - PPCJ da Universidade do Vale do Itajaí - UNIVALI; e dos cursos de Direito do Centro Universitário Uniavan e da Faculdade Sinergia. Advogada. E-mail: heloisegarcia@univali.br
} 
insurgência da sustentabilidade como novo paradigma e a necessidade da instituição do Estado Socioambiental de Direito.

\section{Palavras chave:}

Estado Liberal; Estado Social; Estado Democrático; Paradigma da Sustentabilidade; Estado Socioambiental de Direito.

\section{RESUMEN:}

El objetivo de la presente pesquisa es el análisis de la necesidad de consolidación de un nuevo modelo de Estado de Derecho, frente a las actuales condiciones globales de crisis ecológica y social. El método utilizado para la pesquisa fue el método inductivo. Durante el trabajo será analizada la evolución histórica de los Estado de Derecho Liberal, Social y Democrático, y la forma como esa evolución histórica de los Estado de Derecho Liberal, Social y Democrático, y la forma como esa evolución está ligada a los cambios de paradigma suscitados por las crisis vivenciadas por la humanidad. Considerando la actual crisis ambiental y social vivida mundialmente, será estudiada la insurgencia de la sostenibilidad como nuevo paradigma y la necesidad de la institución del Estado Socio Ambiental de Derecho.

\section{Palabras clave:}

Estado Liberal; Estado Social; Estado Democrático; Paradigma de la Sostenibilidad; Estado Socio Ambiental de Derecho.

\section{ABSTRACT:}

The objective of this research is the analysis of the need to consolidate a new model of State of Law, in face of the current global conditions of ecological and social crisis. The method used for the research was the inductive method. During the work the historical evolution of the States of Law, Liberal, Social and Democratic, will be analyzed, and the way in which this evolution is linked to the paradigm changes provoked by the crises experienced by humanity. Considering the current environmental and social crisis experienced worldwide, the insurgency of sustainability as a new paradigm and the need for the institution of the Socio-Environmental State of Law will be studied.

\section{Keywords:}

Liberal State, Social State; Democratic State; Paradigm of Sustainability; Socio-Environmental State of Law.

\section{INTRODUÇÃO}

O objetivo da presente pesquisa é a análise da necessidade de consolidação de um novo modelo de Estado de Direito, frente às atuais condições globais de crise ecológica e social.

Nesse sentido, será analisada a evolução histórica dos Estados de Direito, conforme os contextos em que estavam inseridos e as mudanças de paradigma suscitados na sociedade ou, em uma análise global, pelas crises vivenciadas pela 
humanidade. Para tanto, serão estudadas a instituição e a transição dos Estados de Direito Liberal, Social e Democrático.

Após, analisar-se-á a atual crise ambiental e social vivida mundialmente e a insurgência da sustentabilidade como novo paradigma global, momento em que se observará em que contexto emergiu a sustentabilidade, bem como o seu potencial axiológico para ser aplicada nesta nova ordem jurídica altamente complexa, plural e transnacionalizada.

Com a consolidação da sustentabilidade como novo paradigma global, nasce a necessidade de uma transformação do atual Estado de Direito que não consegue mais atender às demandas suscitadas pela humanidade.

Por esta razão, o Estado Socioambiental de Direito será estudado, para que se compreenda este novo modelo de Estado, as suas características e se, de fato, poderá sanar os anseios da atual crise que se vive mundialmente, sem, entretanto, esgotar o tema.

A relevância do estudo do presente tema reside na necessidade de apresentar evidências de que a humanidade está se aproximando de um momento de evolução social, que reclama a consolidação de um novo paradigma do Direito e, consequentemente, de um novo Estado de Direito.

As categorias operacionais ou termos estratégicos utilizados e seus conceitos operacionais serão esboçados no desenvolvimento da pesquisa.

A investigação, o tratamento de dados e o relato da pesquisa segue o método indutivo, ${ }^{1}$ acionado com auxílio das técnicas do referente, ${ }^{2}$ da categoria, ${ }^{3}$ do conceito operacional ${ }^{4}$ e da pesquisa bibliográfica. ${ }^{5}$

\section{DA EVOLUÇÃO HISTÓRICA DO ESTADO DE DIREITO EM DECORRÊNCIA DA MUDANÇA DE PARADIGMAS}

Inicialmente, para que se possa compreender o verdadeiro sentido de um paradigma e como ocorreu sua introdução na discussão epistemológica contemporânea, é fundamental o estudo da concepção de paradigma formulada por Thomas Kuhn. ${ }^{6}$

1 "MÉTODO INDUTIVO: base lógica da dinâmica da Pesquisa Científica que consiste em pesquisar e identificar as partes de um fenômeno e coleciona-las de modo a ter uma percepção ou conclusão geral." Conforme Cesar Luiz PASOLD, Metodologia da Pesquisa Jurídica: Teoria e Prática, 13ª edición, Conceito Editorial, Florianópolis, 2015, p. 205.

2 "REFERENTE: explicitação prévia do motivo, objetivo e produto desejado, delimitando o alcance temático e de abordagem para uma atividade intelectual, especialmente para uma pesquisa." Conforme PASOLD, Cesar Luiz, Metodologia da Pesquisa Jurídica: Teoria e Prática, 13 a edición, Conceito Editorial, Florianópolis, 2015, p. 209.

3 "CATEGORIA: palavra ou expressão estratégica à elaboração e/ou à expressão de uma ideia." Conforme PASOLD, Cesar Luiz, Metodologia da Pesquisa Jurídica: Teoria e Prática, 13ª edición, Conceito Editorial, Florianópolis, 2015, p. 197.

4 "CONCEITO OPERACIONAL [COP]: definição estabelecida ou proposta para uma palavra ou expressão, com o propósito de que tal definição seja aceita para os efeitos das ideias expostas." Conforme PASOLD, Cesar Luiz, Metodologia da Pesquisa Jurídica: Teoria e Prática, 13ª edición, Conceito Editorial, Florianópolis, 2015, p. 198.

5 "PESQUISA BIBLIOGRÁFICA: Técnica de investigação em livros, repertórios jurisprudenciais e coletâneas legais." Conforme Cesar Luiz PASOLD, Metodologia da Pesquisa Jurídica: Teoria e Prática, 13ª edición, Conceito Editorial, Florianópolis, 2015, p. 207.

6 KUHN, Thomas, A estrutura das revoluções cientificas, Perspectiva, São Paulo, 2000, p. 43. 
Um paradigma, em seu entendimento, consiste em um modelo de padrão aceito, o qual, em regra, não admite reprodução, na medida em que "é um objeto a ser mais bem articulado e precisado em condições novas ou mais rigorosas".7

Portanto, a cada mudança de paradigma é necessário que o passado seja novamente trabalhado, a fim de que o novo paradigma complemente o anterior. ${ }^{8}$

Para Menelick de Carvalho Netto a noção de paradigma apresenta duplo aspecto, por permitir explicar o desenvolvimento científico comparado a um processo de rupturas, por intermédio da "tematização e explicitação de aspectos centrais dos grandes esquemas gerais de pré-compreensões e visões-de-mundo", consubstanciados no conjunto das condições e circunstâncias das práticas sociais, "que a um só tempo tornam possível a linguagem, a comunicação, e limitam ou condicionam o nosso agir e a nossa percepção de nós mesmos e do mundo". ${ }^{9}$

Utilizando a concepção de paradigma na seara das ciências sociais e do direito, J. Habermas, ${ }^{10}$ mencionado por Marcelo Cattoni, ensina que paradigmas de direito são "as visões exemplares de uma comunidade jurídica que considera como o mesmo sistema de direitos e princípios constitucionais podem ser realizados no contexto percebido de uma dada sociedade". Com efeito, "um paradigma de direito delineia um modelo de sociedade contemporânea para explicar como direitos e princípios constitucionais devem ser concebidos e implementados para que cumpram naquele dado contexto as funções normativamente a eles atribuídas". ${ }^{11}$

Em uma breve análise, conclui-se que os paradigmas foram e são os grandes causadores das mudanças nos modelos de Estado de Direito durante a história, razão pela qual o estudo individual de cada modelo e suas peculiaridades é fundamental para a presente pesquisa.

\subsection{O Estado Liberal de Direito}

Este modelo de Estado institucionalizou-se após a Revolução Francesa de 1789, com o término do Estado Monárquico autoritário e constituiu o primeiro regime jurídico-político da sociedade, materializando novas relações econômicas e sociais: de um lado os capitalistas (burgueses em ascensão) e de outro a realeza (monarcas) e a nobreza (senhores feudais em decadência). ${ }^{12}$

7 KUHN, Thomas, A estrutura das revoluções cientificas, Perspectiva, São Paulo, 2000, p. 44.

8 MAULAZ, Ralph Batista de, "Os paradigmas do Estado de Direito. O Estado Liberal, o Estado Social (socialista) e o Estado Democrático de Direito", en Revista Jus Navigandi, Teresina, ano 15, n. 2628, 11 set. 2010. Disponible en: «https://jus.com.br/artigos/17368». Aceso en: 31 jul. 2017.

9 CARVALHO NETTO, Menelick de, "Requisitos paradigmáticos da interpretação jurídica sob o paradigma do Estado democrático de direito" en Revista de Direito Comparado, Belo Horizonte, n. 3, p. 476, mai., 1999.

10 HABERMAS, Jürgen, Direito e Democracia: entre a facticidade e validade, Tempo Universitário, Rio de Janeiro, 1997, p. 123.

11 HABERMAS, Jürgen, Between facts and norms: contributions to discourse theory of law and democracy, The MIT, Cambridge, 1996. p. 194 e 195. Apud., CATTONI, Marcelo, Direito constitucional, Mandamentos, Belo Horizonte, 2002, p. 54.

12 LA BRADBURY, Leonardo Cacau Santos, "Estados liberal, social e democrático de direito: noções, afinidades e fundamentos" en Revista Jus Navigandi, Teresina, ano 11, n. 1252, 5 dez. 2006, Disponible en: «https:// jus.com.br/artigos/9241». Aceso en: 31 jul. 2017. 
Com o lema "Liberdade, Igualdade e Fraternidade", os reais desejos burguesia estavam resumidos, porquanto almejavam a liberdade individual, a abolição das discriminações e fraternidade dos camponeses e sans-cullotes, ${ }^{13}$ com o intuito de que apoiassem a revolução e lutassem por ela, competindo ao Estado "garantir a certeza nas relações sociais, através da compatibilização dos interesses privados de cada um com o interesse de todos, mas deixar a felicidade ou a busca da felicidade nas mãos de cada indivíduo". ${ }^{14}$

Ao obstar o exercício arbitrário do poder pelos governantes, o Estado de Direito Liberal reconhece, de uma forma mínima, direitos individuais fundamentais, como a vida, a liberdade e a propriedade.

\section{Segundo Norberto Bobbio:}

$\mathrm{Na}$ doutrina liberal, Estado de direito significa não só subordinação dos poderes públicos de qualquer grau às leis gerais do país, limite que é puramente formal, mas também subordinação das leis ao limite material do reconhecimento de alguns direitos fundamentais considerados constitucionalmente, e portanto em linha de princípio invioláveis. ${ }^{15}$

Assim, o Estado Liberal cria os chamados direitos fundamentais de primeira geração.

Consagra-se, ademais, a igualdade de todos perante a lei, proprietários, no mínimo, de si próprios, pondo-se fim aos privilégios de nascimento que prevaleciam $^{16}$ e os indivíduos passam a ser respeitados como sujeitos de direito.

Com o rompimento da ideologia passada, o homem traça seus passos rumo à democracia, buscando concretizar os ideais burgueses referentes às liberdades concretas. ${ }^{17}$

Por conseguinte, a separação de poderes foi salutar para a proteção dos direitos da liberdade, por fracionar o exercício das funções administrativas, legislativas e judiciais e, dentre outras prerrogativas, a segurança jurídica também passou a ser respeitada. ${ }^{18}$

E então, a Constituição passa a ser entendida como uma ordenação normativo-sistemática da comunidade política, que, nas palavras de J. J. Canotilho, pode ser definida como uma "ordenação sistemática e racional da comunidade política através de um documento escrito no qual se declaram as liberdades e os direitos e se fixam os limites do poder político". ${ }^{19}$

13 Sans-culottes (tradução: sem-calças): população pobre de Paris, formada pela massa de artesãos, aprendizes, lojistas, biscateiros e desempregados; teve importante participação nos acontecimentos revolucionários de 1789 a 1794.

14 CATTONI, Marcelo, Direito constitucional, Mandamentos, Belo Horizonte, 2002, p. 55.

15 Norberto BOBBIO, Liberalismo e Democracia, 2a edición, Brasiliense, São Paulo, 1988, pág. 19.

16 CARVALHO NETTO, Menelick de, "Requisitos paradigmáticos da interpretação jurídica sob o paradigma do Estado democrático de direito" en Revista de Direito Comparado, Belo Horizonte, n. 3, p. 476, mai., 1999.

18 MAULAZ, Ralph Batista de, "Os paradigmas do Estado de Direito. O Estado Liberal, o Estado Social (socialista) e o Estado Democrático de Direito", en Revista Jus Navigandi, Teresina, ano 15, n. 2628, 11 set. 2010. Disponible en: «https://jus.com.br/artigos/17368». Aceso en: 31 jul. 2017.

19 CANOTILHO, J. J. Gomes, Direito Constitucional e teoria da Constituição, Almedina, Coimbra, 1999, p. 48. 
Em resumo, o paradigma do Estado Liberal de Direito gera liberdade a todos, isto é, a liberdade, a propriedade e a igualdade são conferidas a todos e encontram sustento na legislação, na separação de poderes e nos direitos e garantias individuais.

\subsection{O Estado Social de Direito}

No paradigma constitucional do Estado Liberal, não obstante o homem tenha alcançado o ideal de liberdade perante o Estado, especialmente com o implemento de um documento formal garantidor de direitos de $1^{\text {a }}$ geração, a condição humana não melhorou muito em relação à noção pré-moderna. ${ }^{20}$

Isso porque a igualdade formal aplicada e o absenteísmo do Estado Liberal agravaram a situação da classe trabalhadora, especialmente diante da expansão do capitalismo, que passou a submeter o trabalhador a condições degradantes. ${ }^{21}$

Essa situação moveu a classe trabalhadora a organizar-se com o objetivo de resistir à exploração, com a possibilidade de uma ruptura drástica do Estado Liberal, em virtude da acentuada adesão de operários do ocidente europeu, colocando-se em risco a ordem liberal com o surgimento de ideias socialistas, comunistas e anarquistas, que "animam os movimentos coletivos de massa cada vez mais significativos e neles reforça com a luta pelos direitos coletivos e sociais". ${ }^{22}$ Consequentemente, torna-se necessário o tratamento desigual aos desiguais na medida de suas desigualdades.

Sobre as semelhanças e diferenças existentes entre estas duas formas de Estado, Gordillo assim enuncia:

A diferença básica entre a concepção clássica do liberalismo e a do Estado de BemEstar é que, enquanto naquela se trata tão-somente de colocar barreiras ao Estado, esquecendo-se de fixar-lhe também obrigações positivas, aqui, sem deixar de manter as barreiras, se lhes agregam finalidades e tarefas às quais antes não sentia obrigado. A identidade básica entre o Estado de Direito e Estado de Bem-Estar, por sua vez, reside em que o segundo toma e mantém do primeiro o respeito aos direitos individuais e é sobre esta base que constrói seus próprios princípios. ${ }^{23}$

Infere-se que o Estado Social (ou do Bem-Estar) e o Estado Liberal, conquanto possuam finalidade diversa, apresentam afinidades, pois ambos destinamse a respeitar os direitos individuais, notadamente o da liberdade, para a edificação de pilares que fundamentam a criação dos direitos sociais. ${ }^{24}$

20 MAULAZ, Ralph Batista de, "Os paradigmas do Estado de Direito. O Estado Liberal, o Estado Social (socialista) e o Estado Democrático de Direito", en Revista Jus Navigandi, Teresina, ano 15, n. 2628, 11 set. 2010. Disponible en: «https://jus.com.br/artigos/17368». Aceso en: 31 jul. 2017.

21 LA BRADBURY, Leonardo Cacau Santos, "Estados liberal, social e democrático de direito: noções, afinidades e fundamentos" en Revista Jus Navigandi, Teresina, ano 11, n. 1252, 5 dez. 2006, Disponible en: «https:// jus.com.br/artigos/9241». Aceso en: 31 jul. 2017.

22 CARVALHO NETTO, Menelick de, "Requisitos paradigmáticos da interpretação jurídica sob o paradigma do Estado democrático de direito" en Revista de Direito Comparado, Belo Horizonte, n. 3, p. 476, mai., 1999.

23 GORDILlO, Agustín, Princípios Gerais de Direito Público, Ed. RT, São Paulo, 1977, p. 74.

24 LA BRADBURY, Leonardo Cacau Santos, "Estados liberal, social e democrático de direito: noções, afinidades e fundamentos" en Revista Jus Navigandi, Teresina, ano 11, n. 1252, 5 dez. 2006, Disponible en: «https:// jus.com.br/artigos/9241». Aceso en: 31 jul. 2017. 
Desse modo, surgem os "direitos de segunda geração", que apresentam a função de melhorar as condições de vida e de trabalho da população em geral, requisitando do Estado a proteção das pessoas exploradas, compreendendo, entre outros, o direito ao trabalho, à saúde, à educação, ao lazer e à moradia, ${ }^{25}$ sendo que a Constituição do México, de 1917, foi a primeira a consagrar os diretos sociais, ainda que a Constituição Alemã de 1919 (de Weimar) seja a mais conhecida. No Brasil, a primeira Constituição a consagrá-los foi a de $1934 .^{26}$

Posteriormente, surge a fase social do constitucionalismo, alicerçada na Constituição da República de Weimar, inaugurando-se o Estado Social de Direito, materializando determinados direitos, gerando a "internalização na legislação de uma igualdade não mais apenas formal, mas tendencialmente material", ${ }^{27}$ não apenas no âmbito dos direitos individuais, na medida em que também reinterpretado o princípio da separação de poderes.

Surgem novos institutos no direito, tais como: os direitos sociais, a função social do contrato, a função social da propriedade, o dirigismo contratual, a legislação econômica pelo Poder Executivo. ${ }^{28}$

Nas palavras de Paulo Cruz, o Estado de Bem-Estar Social "caracteriza-se pela união da tradicional garantia das liberdades individuais com o reconhecimento, como direitos coletivos, de certos serviços sociais que o Estado providencia, pela intervenção, aos cidadãos de modo a proporcionar iguais oportunidades a todos". ${ }^{29}$

Portanto, o Estado Social de Direito institucionalizou-se naquele momento para assegurar direitos sociais e concretizar o ideal da igualdade material aos cidadãos.

\subsection{Estado Democrático de Direito}

Posteriormente à Segunda Guerra Mundial, o paradigma do Estado Social começa a entrar em crise. ${ }^{30}$

Na lição de Paulo Bonavides, o Estado Social não mais atendia de forma efetiva aos anseios democráticos, pois "o Estado Social se compadece com regimes políticos antagônicos, como sejam a democracia, o fascismo e o nacionalsocialismo". ${ }^{31}$

Consequentemente, na tentativa de superar a oposição existente entre Estado Social e o direito formal burguês, houve a criação de uma nova compreensão do modelo constitucional de Estado. ${ }^{32}$

25 Inserida no rol do art. $6^{\circ}$ da C.F./88 por meio da Emenda Constitucional n ${ }^{\circ}$ 26/2000.

26 LA BRADBURY, Leonardo Cacau Santos, "Estados liberal, social e democrático de direito: noções, afinidades e fundamentos" en Revista Jus Navigandi, Teresina, ano 11, n. 1252, 5 dez. 2006, Disponible en: «https:// jus.com.br/artigos/9241». Aceso en: 31 jul. 2017.

27 HABERMAS, Jürgen, Direito e Democracia: entre a facticidade e validade, Tempo Universitário, Rio de Janeiro, 1997, v. 2, p. 127.

28 STRECK Lenio Luiz e MORAIS, Jose Luis Bolzan de, Ciência Política e Teoria do Estado, $8^{\text {a }}$ edición, Saraiva, São Paulo, 2013. p. 76.

29 CRUZ, Paulo Márcio, Política, poder, ideologia e estado contemporâneo, Juruá, Curitiba, 2002. p. 163.

30 CARVALHO NETTO, Menelick de, "Requisitos paradigmáticos da interpretação jurídica sob o paradigma do Estado democrático de direito" en Revista de Direito Comparado, Belo Horizonte, n. 3, p. 476, mai., 1999. BONAVIDES, Paulo, Do Estado liberal ao Estado social, Malheiros, São Paulo, 1996, p. 205 e 206.

32 HABERMAS, Jürgen, Direito e Democracia: entre a facticidade e validade, Tempo Universitário, Rio de Janeiro, 1997, v. 2, p. 131. 
Assim, o Estado Democrático de Direito vem para corrigir as falhas que existiam no Estado Social, o qual não conseguiu garantir a justiça social, tampouco a efetiva participação democrática do povo no processo político. ${ }^{33}$

E assim, consagram-se os direitos de $3^{a}$ geração (direitos ou interesses difusos). Por sua vez, os de $1^{\mathrm{a}}$ e $2^{\mathrm{a}}$ acabam passando por uma releitura, adequando-se ao novo modelo. ${ }^{34}$

Os direitos de terceira geração localizam-se no plano do respeito, apresentando conteúdo fraternal e compreendem os direitos coletivos, ou seja, o Estado passa a tutelar, além dos interesses individuais e sociais, os transindividuais (ou metaindividuais), os quais compreendem, dentre outros, a paz, a autodeterminação dos povos, a moralidade administrativa, o respeito ao meio ambiente ecologicamente equilibrado. ${ }^{35}$

Este modelo de Estado emerge da evolução do Estado Liberal e do Estado Social. Em verdade, cada modelo é o resultado das transformações dos anteriores.

Nessa perspectiva, Menelick de Carvalho Netto salienta que os direitos de $1^{\text {a }}$ geração são revestidos de conotação processual e retomados como direitos de participação no debate público, informando a soberania do paradigma constitucional do Estado Democrático de Direito e seu direito participativo, pluralista e aberto. ${ }^{36}$

O Poder Judiciário tem sua participação ampliada, a fim de que seja concretizado este modelo de Estado. ${ }^{37}$

José Afonso da Silva (1999, p. 123), com precisão, traduz a união que gerou o respectivo modelo:

A configuração do 'Estado Democrático de Direito' não significa apenas unir formalmente os conceitos de Estado Democrático e Estado de Direito. Consiste, na verdade, na criação de um conceito novo, que leva em conta os conceitos dos elementos componentes, mas os supera na medida em que incorpora um componente revolucionário de transformação do 'status quo'.

A teoria adequada ao Estado Democrático de Direito resulta da aproximação da prática de interpretação de textos constitucionais exercida na jurisdição constitucional, ${ }^{38}$ com a inserção de princípios constitucionais.

Nesse pensar, na vertente pós-positiva, o ordenamento jurídico revela-se como um conjunto normativo que engloba regras e princípios, fundindo-se, assim,

33 SILVA, José Afonso da, Curso de Direito Constitucional Positivo, 24a edición, Malheiros, São Paulo, 2005, p. 118.

34 MAULAZ, Ralph Batista de, "Os paradigmas do Estado de Direito. O Estado Liberal, o Estado Social (socialista) e o Estado Democrático de Direito", en Revista Jus Navigandi, Teresina, ano 15, n. 2628, 11 set. 2010. Disponible en: «https://jus.com.br/artigos/17368». Aceso en: 31 jul. 2017.

LA BRADBURY, Leonardo Cacau Santos, "Estados liberal, social e democrático de direito: noções, afinidades e fundamentos" en Revista Jus Navigandi, Teresina, ano 11, n. 1252, 5 dez. 2006, Disponible en: «https:// jus.com.br/artigos/9241». Aceso en: 31 jul. 2017. do Estado democrático de direito" en Revista de Direito Comparado, Belo Horizonte, n. 3, p. 476, mai., 1999. CARVALHO NETTO, Menelick de, "Requisitos paradigmáticos da interpretação jurídica sob o paradigma do Estado democrático de direito" en Revista de Direito Comparado, Belo Horizonte, n. 3, p. 476, mai., 1999.

Cf., GUERRA FILHO, Willis Santiago, Teoria da ciência jurídica, Saraiva, São Paulo, 2001, p. 146; PIMENTA, Roberto Lyrio, Eficácia e aplicabilidade das normas constitucionais programáticas, Max Limonad, São Paulo, 1999, p. 126. 
as diretrizes do Estado Democrático com as do Estado de Direito, tendo em vista que formam uma forte relação de interdependência, como assinala Bobbio:

Estado Liberal e estado democrático são interdependentes em dois modos: na direção que vai do liberalismo à democracia, no sentido de que são necessárias certas liberdades para o exercício correto do poder democrático, e na direção oposta que vai da democracia ao liberalismo, no sentido de que é necessário o poder democrático para garantir a existência e a persistência das liberdades fundamentais. Em outras palavras: é pouco provável que um estado não liberal possa assegurar um correto funcionamento da democracia, e de outra parte é pouco provável que um estado não democrático seja capaz de garantiras liberdades fundamentais. ${ }^{39}$

No Brasil, o Estado Democrático de Direito foi proclamado pela Constituição da República Federativa do Brasil de 1988, em seu art. $1^{\circ}$, o qual, de acordo com José Afonso da Silva, não se trata de "mera promessa de organizar tal Estado, pois a Constituição aí já está proclamando e fundando".40

Carlos Ari Sundfeld ${ }^{41}$ afirma que "o Estado brasileiro de hoje constrói a noção de Estado Social e Democrático de Direito". Isso porque a figura estatal destina-se a atingir determinados direitos sociais, além de garantir a efetiva democracia e o respeito aos direitos e garantias fundamentais.

\section{O NOVO PARADIGMA: SUSTENTABILIDADE}

A partir da década de 70, diante da situação de degradação ambiental do planeta e dos perigos que o desequilíbrio ecológico gera à humanidade, nasce uma consciência ecológica planetária, ${ }^{42}$ resultante da crise ambiental vivida mundialmente, como bem enuncia François Ost:

É que o balanço da saúde do planeta revela-se de tal modo catastrófico, que não é mais possível esconder o facto à população. De todos os lados aparecem os sintomas da maleita: sintoma de febrilidade pelo aquecimento do clima, na sequência do aumento vertiginoso da produção de gases com efeito estufa, como o famoso $\mathrm{CO} 2$, síndroma de imunodeficiência da atmosfera, atacada pelos CFC e outros compostos clorados, doenças cutâneas sob a forma de desflorestação e desertificação, empobrecimento genético devido à redução vertiginosa da biodiversidade, envenenamento do ar, da água e da terra pelos resíduos tóxicos, e sufocação sob as montanhas de lixo... A que se juntam os sintomas mais físicos, vivamente sentidos pelas populações e afectando o quadro de vida, como o aumento dos danos acústicos, o desfeamento das cidades sacrificadas aos automóveis e às promoções imobiliárias, a uniformização das culturas e a banalização das paisagens. ${ }^{43}$

39 BOBBIO, Norberto, O Futuro da Democracia - Uma Defesa das Regras do Jogo, 2ª edición, Paz e Terra, Rio de Janeiro, 1986, p. 20.

40 SILVA, José Afonso da, Curso de Direito Constitucional Positivo, 24 a edición, Malheiros, São Paulo, 2005, p. 119. 
Fritjof Capra afirma que "a destruição ambiental não é somente um efeito colateral, mas um elemento essencial da concepção do capitalismo global" ${ }^{44}$ de modo que a produção capitalista, que tem como objetivo a busca desenfreada pelo lucro, desconsidera a capacidade dos sistemas naturais se recuperarem das degradações sofridas. ${ }^{45}$

O planeta, por sua vez, responde a estes ataques com catástrofes cada vez mais crescentes, tais como: furacões, tsunamis, erupções de vulcões, enchentes, deslizamentos, aquecimento global e mudanças climáticas abruptas. ${ }^{46}$

Os desastres naturais têm se intensificado em todo o mundo, tanto em frequência quanto em intensidade, causando grandes danos econômicos e humanos. ${ }^{47}$ Nesse sentido, o Relatório de Desenvolvimento Humano de 2013, apresentado pelo Programa das Nações Unidas para o Desenvolvimento (PNUD), atestou que o mundo pode viver uma catástrofe ambiental em $2050 . .^{48}$

Apenas em 2011, terremotos seguidos de tsunamis e deslizamentos de terra causaram mais de 20 mil mortes, 1 milhão de pessoas sem casas e prejuízos em torno de US\$ 365 bilhões (R\$ 730 bilhões) nos Estados Unidos da América. ${ }^{49}$ Os pequenos países insulares em desenvolvimento sofreram perdas de até $8 \%$ do Produto Interno Bruto. ${ }^{50}$

Diante disso, muitos estudiosos entendem que a humanidade está se aproximando de um daqueles momentos evolutivos que determinam o surgimento de uma nova idade ou era, ${ }^{51}$ de forma que surge a necessidade da consolidação de um novo paradigma do Direito. ${ }^{52}$

44 CAPRA, Fritjof, As conexões ocultas: ciência para uma vida sustentável, Cultrix, São Paulo, 2005. p. 159.

45 CRUZ, Paulo Marcio; LOPES DE FARIA, Daniela e ITO, Christian Normitsu, "A necessária evolução do Estado de Direito Social teorizado por Herman Heller ao Estado de Direito Socioambiental diante da crise ambiental na sociedade de riscos" em Revista Brasileira de Direito, Passo Fundo, v. 12, n. 1, p. 74-87, jun. 2016, Disponible en: «https://seer.imed.edu.br/index.php/revistadedireito/article/view/1119». Aceso en: 30 jul. 2017.

46 HARDING, Stephan, Terra viva: ciência, intuição e a evolução de Gaia - para uma nova compreensão da vida em nosso planeta, Cultrix, São Paulo, 2008, p. 225.

47 ARMADA, Charles Alexandre Souza, "O estado socioambiental de direito brasileiro e a concretização multidimensional da sustentabilidade" en: Revista Eletrônica Direito e Política, Programa de Pós- Graduação Stricto Sensu em Ciência Jurídica da UNIVALI, Itajaí, v.10, n.1, edição especial de 2015. Disponible en: www.univali.br/direitoepolitica.

48 Programa das Nações Unidas para o Desenvolvimento. Relatório do desenvolvimento humano 2013: a ascensão do sul. Disponível em: «http://www.pnud.org.br/arquivos/rdh-2013.pdf». Acesso em: 23 abr. 2013.

49 Programa das Nações Unidas para o Desenvolvimento. Relatório do desenvolvimento humano 2013: a ascensão do sul. Disponível em: «http://www.pnud.org.br/arquivos/rdh-2013.pdf». Acesso em: 23 abr. 2013.

50 tidimensional da sustentabilidade" en: Revista Eletrônica Direito e Política, Programa de Pós-Graduação Stricto Sensu em Ciência Jurídica da UNIVALI, Itajaí, v.10, n.1, edição especial de 2015. Disponible en: www.univali.br/direitoepolitica.

51 DANTAS, Marcelo Buzaglo; OLIVIERO, Maurizio e CRUZ, Paulo Marcio, "Direito, transnacionalidade e sustentabilidade empática" em: Revista do Direito, Santa Cruz do Sul, v. 2, n. 49, maio 2016. Disponible en: «https://online.unisc.br/seer/index.php/direito/article/view/7911». Aceso en: 30/07/2017.

52 DANTAS, Marcelo Buzaglo; OLIVIERO, Maurizio e CRUZ, Paulo Marcio, "Direito, transnacionalidade e sustentabilidade empática" em: Revista do Direito, Santa Cruz do Sul, v. 2, n. 49, maio 2016. Disponible en: «https://online.unisc.br/seer/index.php/direito/article/view/7911». Aceso en: 30/07/2017. 
E é nesse contexto que emerge naturalmente a sustentabilidade, como grande potencial axiológico para ser aplicada e reconhecida na centralidade desta nova ordem jurídica altamente complexa, plural e transnacionalizada. ${ }^{53}$

Assim, o ser humano deverá evoluir do individualismo liberal, passando pelas experiências de igualdade relativa do Estado de Bem-Estar Social, até alcançar a sustentabilidade. ${ }^{54}$

Aceitar a sustentabilidade como novo paradigma do Direito é reconhecer que o planeta é finito e não tem recursos infindáveis, de forma que a humanidade precisa adotar novos padrões de produção e consumo, que se limitem aos recursos que a biosfera terrestre é capaz de repor, que não comprometam drasticamente o meio ambiente, os biomas do planeta, os seres vivos que neles vivem, as cadeias alimentares e reprodutivas e que não degradem os seres humanos, a fim de se preservar os direitos das futuras gerações. ${ }^{55}$

O novo paradigma da sustentabilidade exige, também, uma readequação qualitativa e estratégica do próprio Direito, que, enquanto instrumento de controle social estatal emanado de um ente soberanamente isolado no planeta, já não produz mais respostas eficazes para assegurar um futuro sustentável. ${ }^{56}$

É necessária, portanto, a construção e a consolidação de uma nova concepção de sustentabilidade global, como paradigma de aproximação entre os povos e culturas, e na participação do cidadão de forma consciente e reflexiva na gestão política, econômica e social. ${ }^{57}$

Destaca-se, nesse sentido, que a sustentabilidade deve ser construída a partir de diferentes dimensões, conforme Juarez Freitas: ${ }^{58}$

A sustentabilidade é multidimensional (ou seja, é jurídico-política, ética, social, econômica e ambiental), o que pressupõe, antes de tudo, uma reviravolta hermenêutica habilitada a produzir o descarte de pré-compreensões espúrias e unidimensionais, com a libertação de tudo o que impede o cumprimento alastrado da sustentabilidade como princípio constitucional, na cena concreta. Afinal, para crises sistêmicas, impõem-se soluções sistêmicas, estruturais e interdisciplinares, cooperativas e globais, com o engajamento de todos, não apenas dos governos.

Gabriel Ferrer, assim como a maioria dos doutrinadores, entende que o conceito de sustentabilidade precisa ser compreendido em sua tripla dimensão: a

53 CRUZ, Paulo Márcio e BODNAR, Zenildo, "O novo paradigma de Direito na pós-modernidade” en: RECHTD/ UNISINOS. Revista de Estudos Constitucionais, Hermenêutica e Teoria do Direito, Porto Alegre, v. 3, p. 75-83, 2011.

54 DANTAS, Marcelo Buzaglo; OLIVIERO, Maurizio e CRUZ Paulo Marcio, "Direito, transnacionalidade e sustentabilidade empática" em: Revista do Direito, Santa Cruz do Sul, v. 2, n. 49, maio 2016. Disponible en: «https://online.unisc.br/seer/index.php/direito/article/view/7911». Aceso en: 30/07/2017.

55 NOVAES, Washington, "Agenda 21: um novo modelo de civilização" en: MELLO, Celso de Albuquerque (Coord.), Anuário: direito e globalização, 1: a soberania, Renovar, Rio de Janeiro, 1999. p. 324.

56 DANTAS, Marcelo Buzaglo; OLIVIERO, Maurizio e CRUZ, Paulo Marcio, "Direito, transnacionalidade e sustentabilidade empática" em: Revista do Direito, Santa Cruz do Sul, v. 2, n. 49, maio 2016. Disponible en: «https://online.unisc.br/seer/index.php/direito/article/view/7911». Aceso en: 30/07/2017.

57 CRUZ, Paulo Márcio e OLIVIERO, Maurizio, "Reflexões sobre o direito transnacional" en: Revista Novos Estudos Jurídicos, Itajaí, v. 17, n. 1 - Edição Especial Rio +20, p. 18-28, 2012.

58 FREITAS, Juarez, Sustentabilidade: direito ao futuro, $2^{\mathrm{a}}$ edición, Fórum, Belo Horizonte, 2012, p. 50. 
dimensão ambiental, relacionando-se com a sobrevivência; a dimensão econômica, determinando a criação e a distribuição da riqueza; e, finalmente, a dimensão social, significando a governança e a luta contra a exclusão. ${ }^{59}$

Por conseguinte, é possível afirmar que a sustentabilidade consolida-se como o atual paradigma, tornando necessária, portanto, a formação de um novo modelo de Estado de Direito, destinado a atender aos anseios impostos pela atual crise ecológica mundial.

Dessa forma, num momento particular da história do planeta, nasce um novo modelo de Estado, o Estado Socioambiental de Direito.

\section{ESTADO SOCIOAMBIENTAL DE DIREITO}

No decorrer desta pesquisa, pode-se observar que o Estado de Direito não é uma obra acabada, ele está em constante processo de evolução, acompanhando as necessidades da população e incorporando novos valores, de modo a adaptar sua estrutura. $^{60}$

Diante da complexidade da atual crise mundial, referida no item anterior, os paradigmas do Estado Liberal e do Estado Social não são mais suficientes para suportar a demanda das questões humanas, sociais e ambientais difundidas no planeta. Nem mesmo o Estado Democrático de Direito, por ter constitucionalizado e buscado dar efetividade a tais paradigmas, é o bastante para tal reivindicação. Com o novo paradigma da sustentabilidade, há a necessidade de se falar em um novo modelo de Estado de Direito: O Estado Socioambiental.

O Estado Socioambiental de Direito tem por marco axiológico a solidariedade e, portanto, funda-se nos direitos difusos de terceira geração, como, por exemplo, o meio ambiente ecologicamente equilibrado, a paz e o desenvolvimento. Dessa forma, pode-se afirmar que cada forma de estruturação do Estado de Direito corresponde a um lema da Revolução Francesa: "liberdade, igualdade e fraternidade". 61

Ingo Wolfgang Sarlet e Tiago Fensterseifer corroboram com esse entendimento ao afirmarem:

No tocante ao modelo contemporâneo de Estado de Direito, é possível aderir à ideia de superação do modelo do Estado Social (que, por sua vez, já havia superado o Estado Liberal) - pelo menos na forma assumida após a Segunda Grande Guerrapor um modelo de Estado Socioambiental, também designado por alguns de PósSocial, que, em verdade, não abandona as conquistas dos demais modelos de Estado de Direito em termos de salvaguarda da dignidade humana, mas apenas agrega

59 FERRER, Gabriel Real, "La construcción del Derecho Ambiental” en: Revista Aranzadi de Derecho Ambiental, Pamplona, Espanã, n. 1, 2002, pp. 73-94.

60 FERREIRA, Heline Sivini e FERREIRA, Maria Leonor Paes Cavalcanti, "Mudanças climáticas e biocombustíveis: considerações sobre a sustentabilidade forte no Estado de Direito Ambiental" en: Revista de Direito Ambiental, São Paulo, v. 59, n. 200, jul./set. 2010.

61 PORTANOVA, Rogério, "Direitos humanos e meio ambiente: uma revolução de paradigma para o século XXI" en: LEITE, José Rubens Morato; BELLO FILHO, Ney Barros. (Orgs.), Direito Ambiental Contemporâneo, Manole, Barueri, 2004. p. 621-642. 
a elas uma dimensão ecológica, comprometendo-se com a estabilização e prevenção do quadro de riscos e degradação ecológica. ${ }^{62}$

Os autores entendem que de acordo com as diferentes dimensões (liberal, social e ecológica) dos direitos fundamentais, o seu processo de afirmação histórica reforça a caracterização constitucional do Estado Socioambiental, em superação aos modelos de Estado Liberal e Social. ${ }^{63}$

Logo, o marco jurídico-constitucional socioambiental ajusta-se à necessidade da tutela e promoção - integrada e interdependente - dos direitos sociais e dos direitos ambientais num mesmo projeto jurídico-político para o desenvolvimento humano em padrões sustentáveis, de forma que, em uma perspectiva integrada, falar em direitos fundamentais socioambientais é o mesmo que falar em direitos fundamentais econômicos, sociais, culturais e ambientais (DESCA) ${ }^{64}$

É possível, portanto, destacar o surgimento de um constitucionalismo socioambiental, superando o modelo do constitucionalismo social, designadamente para corrigir o quadro de desigualdade e degradação humana em termos de acesso às condições mínimas de bem-estar. ${ }^{65}$

Considerando que a função do Estado Social não se esgotou, havendo ainda um número considerável da população mundial que vive em condições miseráveis, sem ter assegurado um mínimo existencial dos direitos sociais, faz-se a opção pelo termo Estado Socioambiental de Direito em vez de puramente Estado Ambiental de Direito. ${ }^{66}$

Isso porque é evidente que a questão ambiental não pode ser dissociada da social, conforme bem destaca Amartya Sen: ${ }^{67}$

Existem problemas novos convivendo com antigos-a persistência da pobreza e de necessidades essenciais não satisfeitas, fomes coletivas [...] e ameaças cada vez mais graves ao nosso meio ambiente e à sustentabilidade de nossa vida econômica e social.

Nesse contexto, ao analisar o Brasil, Luís Roberto Barroso afirma que, "no país da malária, da seca, da miséria absoluta, dos menores de rua, do drama fundiário, dos sem-terra, há por certo espaço para mais uma preocupação moderna: a degradação do planeta". ${ }^{68}$

62 SARLET, Ingo Wolfgang e FENSTERSEIFER, Tiago, Direito Constitucional Ambiental: Constituição, Direitos Fundamentais e Proteção do Ambiente, $3^{\mathrm{a}}$ edición, Revista dos Tribunais, São Paulo, 2013, pp. 53-54. SARLET, Ingo Wolfgang e FENSTERSEIFER, Tiago, Direito Constitucional Ambiental: Constituição, Direitos Fundamentais e Proteção do Ambiente, $3^{\text {a }}$ edición, Revista dos Tribunais, São Paulo, 2013, p. 54.

64 SARLET, Ingo Wolfgang e FENSTERSEIFER, Tiago, Direito Constitucional Ambiental: Constituição, Direitos Fundamentais e Proteção do Ambiente, $3^{\text {a }}$ edición, Revista dos Tribunais, São Paulo, 2013, p. 54.

65 SARLET, Ingo Wolfgang e FENSTERSEIFER, Tiago, Direito Constitucional Ambiental: Constituição, Direitos Fundamentais e Proteção do Ambiente, $3^{\mathrm{a}}$ edición, Revista dos Tribunais, São Paulo, 2013, p. 54.

66 FENSTERSEIFER, Tiago, "Estado Socioambiental de Direito e o princípio da solidariedade como seu marco jurídico-constitucional" en: Revista Brasileira de Direitos Fundamentais e Justiça, Porto Alegre, n. 2, jan./ mar. 2008, pp. 132-157.

67 SEN, Amartya, Desenvolvimento como liberdade, Companhia das Letras, São Paulo, 2000, p. 9.

68 BARROSO, Luis Roberto, “A proteção do meio ambiente na Constituição brasileira" en: Revista de Direito Constitucional e Internacional, São Paulo, ano 1, v. 115, out./dez. 1992. 
Dessa forma, o Estado Socioambiental busca ter uma visão holística dos problemas da sociedade atual e do ordenamento jurídico, visando a proteger tanto a biodiversidade quanto a sociodiversidade, ${ }^{69}$ podendo "ser compreendido como produto de novas reivindicações fundamentais do ser humano e particularizado pela ênfase que confere à proteção do meio ambiente"..$^{70}$

Neste modelo de Estado de Direito a proteção ambiental ocupa lugar fundamental na ordem constitucional, de forma que a preservação das condições ambientais passa a balizar as ações estatais e as políticas públicas, a fim de permitir uma existência digna às gerações futuras. ${ }^{71}$

O comando constitucional expresso no art. 225, caput, da CRFB/88, tem especial relevância, pois adota uma concepção integrada do meio ambiente, prevendo responsabilidades e encargos ambientais compartilhados entre Estado e sociedade, ${ }^{72}$ quando subscreve que:

Todos têm direito ao meio ambiente ecologicamente equilibrado, bem de uso comum do povo e essencial à sadia qualidade de vida, impondo-se ao Poder Público e à coletividade o dever de defendê-lo e preservá-lo para as presentes e futuras gerações. $^{73}$

Observa-se, da leitura deste dispositivo, que, com relação ao direito ao meio ambiente ecologicamente equilibrado, a $\mathrm{CRFB} / 88$ prevê uma nova formulação subjetiva-objetiva, em que a dimensão subjetiva é o próprio direito e a dimensão objetiva se traduz no dever, de forma a harmonizar duas dimensões que são necessariamente complementares. ${ }^{74}$

Dessa forma, quando a Carta Constitucional determina que é dever do Poder Público e da coletividade proteger o meio ambiente observa-se a enunciação de um agir integrativo, com responsabilidades compartilhadas, incentivando a cidadania ambiental e a democracia participativa, de forma a preencher as exigências de um Estado Socioambiental de Direito. ${ }^{75}$

$\overline{69}$ SANTILLI, Juliana, Socioambientalismo e novos direitos: proteção jurídica à diversidade biológica e cultural, Peirópolis, São Paulo, 2005, pp. 91-92.

70 FERREIRA, Heline Sivini, Desvendando os organismos transgênicos: as interferências da sociedade de risco no Estado de Direito Ambiental Brasileiro, Forense Universitária, Rio de Janeiro, 2010, p. 161.

71 WOLKMER, Maria de Fátima Schumacher e PAULITSCH, Nicole da Silva, "O Estado de Direito Socioambiental e a Governança ambiental: ponderações acerca da judicialização das políticas públicas ambientais e da atuação do Poder Judiciário" en: Revista Novos Estudos Jurídicos, v. 18, n. 2, pp. 256-268, mai-ago 2013, pp. 259 e 260.

72 SARLET, Ingo Wolfgang e FENSTERSEIFER, Tiago, Direito Constitucional Ambiental: Constituição, Direitos Fundamentais e Proteção do Ambiente, $3^{\text {a }}$ edición, Revista dos Tribunais, São Paulo, 2013, pp. 55 e 56.

73 BRASIL, Constituição Federal da República Federativa do Brasil, Disponible en: «http://www.planalto.gov. br/ccivil_03/constituicao/constituicao. htm». Aceso en: 20 out. 15.

74 LEITE, José Rubens Morato e FERREIRA, Heline Sivini. "Tendências e perspectivas do Estado de Direito Ambiental no Brasil” en: FERREIRA, Heline Sivini; LEITE, José Rubens Morato; BORATTI, Larissa Verri. (Orgs.) Estado de Direito Ambiental: tendências, Forense Universitária, Rio de Janeiro, 2010, p. 20.

75 LEITE, José Rubens Morato; FERREIRA, Heline Sivini. "Tendências e perspectivas do Estado de Direito Ambiental no Brasil” en: FERREIRA, Heline Sivini; LEITE, José Rubens Morato; BORATTI, Larissa Verri. (Orgs.) Estado de Direito Ambiental: tendências, Forense Universitária, Rio de Janeiro, 2010, pp. 20-26. 
Assim, o Estado Socioambiental de Direito surge como uma resposta à crise ambiental desencadeada na sociedade de risco pela irresponsabilidade organizada, tratando-se da reformulação de um dos pilares do Estado de forma a inserir o direito das futuras gerações ao meio ambiente ecologicamente equilibrado e o desenvolvimento sustentável na pauta política. ${ }^{76}$

Este modelo de Estado de Direto deve impulsionar a sociedade para uma mudança de paradigma em nível social, permitindo a consolidação da participação popular na decisão de assuntos de caráter ambiental e em nível ambiental, consolidando uma atuação mais solidária e sustentável. ${ }^{77}$

Entretanto, apesar dos fundamentos constitucionais analisados, "o Estado de Direito do Ambiente é uma construção teórica que se projeta no mundo real ainda como devir". ${ }^{78}$ Trata-se de um modelo, que apesar de seu caráter abstrato, tem importância como paradigma para compreender melhor a crise ambiental na sociedade de risco. ${ }^{79}$

O modelo de Estado Socioambiental de Direito traz esperança e alternativas para que seja possível visualizar um futuro em que os riscos são gerenciados em uma sociedade reflexiva e participativa. ${ }^{80}$

Consoante as premissas lançadas, há a necessidade de transcender de um pacto social para um pacto socioambiental, com o intuito de contemplar o novo papel que o Estado e a sociedade desempenham no âmbito do Estado Socioambiental de Direito.

Portanto, é fundamental a projeção de uma nova postura política e jurídica para a sociedade civil, que, especialmente sob o marco normativo da solidariedade, deverá compartilhar com o Estado, ainda que em menor intensidade, a carga de responsabilidades e deveres de tutela do ambiente para a atual geração e às futuras. ${ }^{81}$

\section{CONSIDERAÇÕES FINAIS}

Por meio da presente pesquisa, pôde-se observar que, durante a história da humanidade, os Estados de Direito se renovaram conforme as mudanças de

76 FERREIRA, Heline Sivini, Desvendando os organismos transgênicos: as interferências da sociedade de risco no Estado de Direito Ambiental Brasileiro, Forense Universitária, Rio de Janeiro, 2010, p. 160.

77 ARMADA, Charles Alexandre Souza e SILVA, Carlos Roberto da, "O Estado Socioambiental de Direito" en: DANTAS, Marcelo Buzaglo; SOUZA, Maria Claudia da Silva Antunes de; PILAU SOBRINHO, Liton Lanes. (Org.), Transnacionalidade, direito ambiental e sustentabilidade: contribuições para a discussão na sociedade hipercomplexa, Ed. Universidade de Passo Fundo, Passo Fundo, 2014.

78 LEITE, José Rubens Morato, "Sociedade de risco e Estado" en: CANOTILHO, José Joaquim Gomes; LEITE, José Rubens Morato. (Orgs.), Direito Constitucional Ambiental Brasileiro, Saraiva, São Paulo, 2011, p. 169.

79 CRUZ, Paulo Marcio; DE FARIA, Daniela Lopes e ITO, Christian Normitsu, "A necessária evolução do Estado de Direito Social teorizado por Herman Heller ao Estado de Direito Socioambiental diante da crise ambiental na sociedade de riscos" em Revista Brasileira de Direito, Passo Fundo, v. 12, n. 1, p. 74-87, jun. 2016, Disponible en: «https://seer.imed.edu.br/index.php/revistadedireito/article/view/1119». Aceso en: 30 jul. 2017.

80 FERREIRA, Heline Sivini, Desvendando os organismos transgênicos: as interferências da sociedade de risco no Estado de Direito Ambiental Brasileiro, Forense Universitária, Rio de Janeiro, 2010, p. 160.

81 SARLET, Ingo Wolfgang e FENSTERSEIFER, Tiago, Direito Constitucional Ambiental: Constituição, Direitos Fundamentais e Proteção do Ambiente, $3^{\text {a }}$ edición, Revista dos Tribunais, São Paulo, 2013, p. 55. 
paradigma suscitados na sociedade ou, em uma análise global, pelas crises vivenciadas pela humanidade.

Os paradigmas de direito têm a função de delinear um modelo de sociedade contemporânea para explicar como direitos e princípios constitucionais devem ser concebidos e implementados para que cumpram naquele dado contexto as funções normativamente a eles atribuídas.

Assim, percorrendo a evolução histórica dos Estados de Direito, observou-se que o Estado Liberal propugnava a liberdade e a luta contra os privilégios do clero e da nobreza, instituindo os chamados direitos fundamentais de primeira geração. Contudo, com o passar do tempo, notou-se que a liberdade econômica deu azo a uma nova forma de subjugação dos trabalhadores, causando injustiças. Diante disso, surgiu o Estado de Bem-Estar Social, cujo grande lema é a igualdade material, e não meramente formal. Ganharam relevância neste contexto os direitos fundamentais de segunda geração, ou, em outras palavras, os direitos sociais, que devem ser promovidos pelo Estado.

Posteriormente à Segunda Guerra Mundial, o paradigma do Estado Social começa a entrar em crise, o Estado Social não mais atendia de forma efetiva aos anseios democráticos. Assim, o Estado Democrático de Direito vem para corrigir as falhas que existiam no Estado Social, o qual não conseguiu garantir a justiça social, tampouco a efetiva participação democrática do povo no processo político.

Todavia, observou-se que, devido à produção capitalista, cujo objetivo consiste na busca desenfreada pelo lucro, a situação global de degradação ambiental começou a se agravar e o planeta, por sua vez, respondeu a estes ataques com catástrofes cada vez mais crescentes.

A partir da década de 70, a preocupação com os perigos que o desequilíbrio ecológico impõem ao ser humano, fez nascer uma consciência ecológica planetária, resultante da crise ambiental vivida mundialmente.

E é nesse contexto que emerge naturalmente a sustentabilidade, em suas dimensões social, econômica e ambiental, como grande potencial axiológico para ser aplicada e reconhecida na centralidade desta nova ordem jurídica altamente complexa, plural e transnacionalizada. Consolida-se, assim, o atual paradigma.

Diante da complexidade da atual crise mundial, os paradigmas do Estado Liberal e do Estado Social não são mais suficientes para atender à demanda das questões humanas, sociais e ambientais difundidas no planeja. Nem mesmo o Estado Democrático de Direito, por ter constitucionalizado e buscado dar efetividade a tais paradigmas, é o bastante para tal reivindicação. Com o novo paradigma da sustentabilidade, há a necessidade de se falar em um novo modelo de Estado de Direito: O Estado Socioambiental.

Observou-se que o Estado Socioambiental de Direito busca ter uma visão holística dos problemas da sociedade atual e do ordenamento jurídico, visando a proteger tanto a biodiversidade quanto a sociodiversidade, podendo ser compreendido como produto de novas reivindicações fundamentais do ser humano e particularizado pela ênfase que confere proteção ao meio ambiente. 
De acordo com as premissas lançadas, entende-se que há a necessidade de transcender de um pacto social para um pacto socioambiental, em vista de contemplar o novo papel que o Estado e a sociedade desempenham no âmbito do Estado Socioambiental de Direito. Deve-se projetar uma nova postura política e jurídica para a sociedade civil, que, especialmente sob o marco normativo da solidariedade, deverá compartilhar com o Estado, ainda que em menor intensidade, a carga de responsabilidades e deveres de tutela do ambiente para a atual geração e às futuras.

\section{REFERENNCIAS DAS FONTES CITADAS}

ARMADA, Charles Alexandre Souza, "O estado socioambiental de direito brasileiro e a concretização multidimensional da sustentabilidade" en: Revista Eletrônica Direito e Política, Programa de Pós-Graduação Stricto Sensu em Ciência Jurídica da UNIVALI, Itajaí, v.10, n.1, edição especial de 2015. Disponible en: www.univali.br/direitoepolitica.

e SILVA, Carlos Roberto da, "O Estado Socioambiental de Direito" en: DANTAS, Marcelo Buzaglo; SOUZA, Maria Claudia da Silva Antunes de; PILAU SOBRINHO, Liton Lanes. (Org.), Transnacionalidade, direito ambiental e sustentabilidade: contribuições para a discussão na sociedade hipercomple$x a$, Ed. Universidade de Passo Fundo, Passo Fundo, 2014.

BARROSO, Luis Roberto, "A proteção do meio ambiente na Constituição brasileira” en: Revista de Direito Constitucional e Internacional, São Paulo, ano 1, v. 115, out./dez. 1992.

BOBBIO, Norberto, Liberalismo e Democracia, $2^{\text {a }}$ edición, Brasiliense, São Pau$10,1988$.

, O Futuro da Democracia - Uma Defesa das Regras do Jogo, 2a edición, Paz e Terra, Rio de Janeiro, 1986.

BONAVIDES, Paulo, Do Estado liberal ao Estado social, Malheiros, São Paulo, 1996.

BRASIL, Constituição Federal da República Federativa do Brasil, Disponible en: «http://www.planalto.gov.br/ccivil_03/constituicao/constituicao.htm». Aceso en: 20 out. 15.

CANOTILHO, J. J. Gomes, Direito Constitucional e teoria da Constituição, Almedina, Coimbra, 1999.

CAPRA, Fritjof, As conexões ocultas: ciência para uma vida sustentável, Cultrix, São Paulo, 2005.

CARVALHO NETTO, Menelick de, "Requisitos paradigmáticos da interpretação jurídica sob o paradigma do Estado democrático de direito" en Revista de Direito Comparado, Belo Horizonte, n. 3, p. 476, mai., 1999.

CATTONI, Marcelo, Direito constitucional, Mandamentos, Belo Horizonte, 2002. CRUZ, Paulo Márcio, Política, poder, ideologia e estado contemporâneo, Juruá, Curitiba, 2002. 
; DE FARIA, Daniela Lopes e ITO, Christian Normitsu. “A necessária evolução do Estado de Direito Social teorizado por Herman Heller ao Estado de Direito Socioambiental diante da crise ambiental na sociedade de riscos" em Revista Brasileira de Direito, Passo Fundo, v. 12, n. 1, pp. 74-87, jun. 2016, Disponible en: «https://seer.imed.edu.br/index.php/revistadedireito/article/ view/1119». Aceso en: 30 jul. 2017.

; BODNAR, Z, "O novo paradigma de Direito na pós-modernidade" en: $R E-$ CHTD/UNISINOS. Revista de Estudos Constitucionais, Hermenêutica e Teoria do Direito, Porto Alegre, v. 3, pp. 75-83, 2011.

; OLIVIERO, Maurizio. "Reflexões sobre o direito transnacional" en: Revista Novos Estudos Jurídicos, Itajaí, v. 17, n. 1 - Edição Especial Rio +20, pp. 18-28, 2012.

DANTAS, Marcelo Buzaglo; OLIVIERO, Maurizio; CRUZ, Paulo Marcio. "Direito, transnacionalidade e sustentabilidade empática" em: Revista do Direito, Santa Cruz do Sul, v. 2, n. 49, maio 2016. Disponible en: «https://online.unisc. br/seer/index.php/direito/article/view/7911». Aceso en: 30/07/2017.

FENSTERSEIFER, Tiago, "Estado Socioambiental de Direito e o princípio da solidariedade como seu marco jurídico-constitucional" en: Revista Brasileira de Direitos Fundamentais e Justiça, Porto Alegre, n. 2, jan./mar. 2008, pp. 132-157.

FERREIRA, Heline Sivini, Desvendando os organismos transgênicos: as interferências da sociedade de risco no Estado de Direito Ambiental Brasileiro, Forense Universitária, Rio de Janeiro, 2010.

e FERREIRA, Maria Leonor Paes Cavalcanti, "Mudanças climáticas e biocombustíveis: considerações sobre a sustentabilidade forte no Estado de Direito Ambiental" en: Revista de Direito Ambiental, São Paulo, v. 59, n. 200, jul./ set. 2010.

FERRER, Gabriel Real, "La construcción del Derecho Ambiental” en: Revista Aranzadi de Derecho Ambiental, Pamplona, Espanã, n. 1, 2002

FREITAS, Juarez, Sustentabilidade: direito ao futuro, $2^{\mathrm{a}}$ edición, Fórum, Belo Horizonte, 2012

GORDILlO, Agustín, Princípios Gerais de Direito Público, Ed. RT, São Paulo, 1977.

GUERRA FILHO, Willis Santiago, Teoria da ciência jurídica, Saraiva, São Paulo, 2001.

HABERMAS, Jürgen, Direito e Democracia: entre a facticidade e validade, Tempo Universitário, Rio de Janeiro, 1997.

HARDING, Stephan, Terra viva: ciência, intuição e a evolução de Gaia - para uma nova compreensão da vida em nosso planeta, Cultrix, São Paulo, 2008

KUHN, Thomas, A estrutura das revoluções científicas, Perspectiva, São Paulo, 2000.

LA BRADBURY, Leonardo Cacau Santos, "Estados liberal, social e democrático de direito: noções, afinidades e fundamentos" en Revista Jus Navigandi, Teresina, ano 11, n. 1252, 5 dez. 2006, Disponible en: «https://jus.com.br/ artigos/9241». Aceso en: 31 jul. 2017. 
LEITE, José Rubens Morato "Sociedade de risco e Estado" en: CANOTILHO, José Joaquim Gomes; LEITE, José Rubens Morato. (Orgs.), Direito Constitucional Ambiental Brasileiro, Saraiva, São Paulo, 2011.

LEITE, José Rubens Morato; FERREIRA, Heline Sivini. "Tendências e perspectivas do Estado de Direito Ambiental no Brasil" en: FERREIRA, Heline Sivini; LEITE, José Rubens Morato; BORATTI, Larissa Verri. (Orgs.) Estado de Direito Ambiental: tendências, Forense Universitária, Rio de Janeiro, 2010 MAULAZ, Ralph Batista de, "Os paradigmas do Estado de Direito. O Estado Liberal, o Estado Social (socialista) e o Estado Democrático de Direito", en Revista Jus Navigandi, Teresina, ano 15, n. 2628, 11 set. 2010. Disponible en: «https://jus.com.br/artigos/17368». Aceso en: 31 jul. 2017.

MORIN, Edgar; KERN, Anne Brigitte, Terra-Pátria, Sulina, Porto Alegre, 2005.

NOVAES, Washington, "Agenda 21: um novo modelo de civilização" en: MELLO, Celso de Albuquerque (Coord.), Anuário: direito e globalização, 1: a soberania, Renovar, Rio de Janeiro, 1999

OST, François, A natureza à margem da lei: a ecologia à prova do Direito, Instituto Piaget, Lisboa, 1997

PORTANOVA, Rogério, "Direitos humanos e meio ambiente: uma revolução de paradigma para o século XXI" en: LEITE, José Rubens Morato; BELLO FILHO, Ney Barros. (Orgs.), Direito Ambiental Contemporâneo, Manole, Barueri, 2004. pp. 621-642

PASOLD, Cesar Luiz, Metodologia da Pesquisa Jurídica: Teoria e Prática, $13^{\mathrm{a}}$ edición, Conceito Editorial, Florianópolis, 2015.

PIMENTA, Roberto Lyrio, Eficácia e aplicabilidade das normas constitucionais programáticas, Max Limonad, São Paulo, 1999

SANTILLI, Juliana, Socioambientalismo e novos direitos: proteção jurídica à diversidade biológica e cultural, Peirópolis, São Paulo, 2005

SARLET, Ingo Wolfgang e FENSTERSEIFER, Tiago, Direito Constitucional Ambiental: Constituição, Direitos Fundamentais e Proteção do Ambiente, $3^{\mathrm{a}}$ edición, Revista dos Tribunais, São Paulo, 2013

SEN, Amartya, Desenvolvimento como liberdade, Companhia das Letras, São Paulo, 2000

SILVA, José Afonso da, Curso de Direito Constitucional Positivo, 24a edición, Malheiros, São Paulo, 2005

STRECK, Lenio Luiz; MORAIS, Jose Luis Bolzan de, Ciência Política e Teoria do Estado, 8 a edición, Saraiva, São Paulo, 2013.

SUNDFELD, Carlos Ari, Fundamentos de Direito Público, $4^{\mathrm{a}}$ edición, Malheiros, São Paulo

WOLKMER, Maria de Fátima Schumacher e PAULITSCH, Nicole da Silva. "O Estado de Direito Socioambiental e a Governança ambiental: ponderações acerca da judicialização das políticas públicas ambientais e da atuação do Poder Judiciário" en: Revista Novos Estudos Jurídicos, v. 18, n. 2, pp. 256268, mai-ago 2013 